\title{
Discriminated Individuals: Others' Dispositional and Situational Attributions by Time and Place
}

\author{
Fernando Gomez", Luis A. Vega \\ Department of Psychology, California State University, Bakersfield, 93311, California, United States
}

Received March 10, 2020; Revised May 4, 2020; Accepted May 13, 2020

Copyright $(2020$ by authors, all rights reserved. Authors agree that this article remains permanently open access under the terms of the Creative Commons Attribution License 4.0 International License

\begin{abstract}
We used a social psychological approach to examine keywords that across time, place, and people have been used to disempower or empower individuals. Using a consensus model and face validity, two raters chose a purposeful sample of 10 sources to do a critical case analysis (Patton, 2002) consisting of books, articles, or monographs that were located using the following labels: racism, science, history, racial identification, inferiority, social issues, phrenology, psychology, prejudice, discrimination and criminal. In all, 108 keywords were identified as uniquely describing empowering and disempowering label attributes (100\% inter-rater agreement). Each keyword was classified according to term denoted by word (noun or adjective), internal and external perspective (biological or sociological), and target (humanize, genocide, dehumanize, suppression). Moreover, the purpose of this qualitative research was to identify how these terms were employed to establish a status of inferiority and to validate the suppression of native populations, minorities, and other non-White groups and target of the label given. The results mainly depicted that psychology has been used to substantiate racists agendas; however, it can promote empowerment by encouraging social awareness of the underlying racial issues.
\end{abstract}

Keywords Racism, Ethnocentrism, Empowering, Disempowering, Social Status

\section{Introduction}

Allport (1954) stated that negative racial prejudice is an incurable bigotry in his classic book, the Nature of Prejudice. The longevity of its premises remains true today. We name, label, target, categorize, disempower, dehumanize, and kill others simply because they fit the label of other. Thus, the purpose of the study is to examine how terms were employed to establish a status of inferiority in order to validate the suppression of native populations, minorities, and other groups that were non-White and what was the target of the label (i.e., humanized, genocide, dehumanize, and oppression). The designation of labels to individuals throughout history has brought prejudice and discriminatory behavior towards the groups affected. Moreover, it is easier to create labels for hated groups rather than a single individual because it is easy to empathize with one person than with an entire group (Allport, 1954). In addition, the labeling of groups can be taken advantage of by powerful individuals who are willing to use it as an advantage for social and political gain for their agendas.

As it was true then and now, Allport (1954) asserted that "Demagogues candidates" used the labeling of fear groups in order to create discourse by blaming the labeled groups as the causer of mishaps, and to make them scapegoats of perceived social ills. In the United States, demagogues have sought to divide people, by calling for actions such as, "vote for me, or the reds [communists, Negroes, Catholics] will get control of the government" (p.420). In this situation, the word "reds" is used as a label to create prejudice towards disenfranchised groups such as Blacks and Catholics in order to create a conflict between us (his/her supporter) and associate them with the scapegoats (Pettigrew, 1978).

Similarly, name-calling and creating labels for migrants for personal gain are what politicians have been doing the world over. President Jackson in the 1800's called Native American savages and beast, Senator McCarthy in the 1950 s created what became as the Red Scare, and more recently, President Trump refer to Mexicans as "Rapists," in order to acquire the funds necessary to create the southern border wall, calling young immigrants as "Too lazy" (Colvin, 2018). President Trump winning the presidential nomination by dehumanizing immigrants shows how strong labels are. This paper will analyze how negative labels have been used around the world, examine 
internal and external labels, the different target of labels, and use content analysis as the method to show that viable categorizations do emerge that can be defined on a continuum of disempowering to empowering of those who are labeled as Other. We used purposeful sampling of critical case analysis (Patton, 2002), an approach that relies on "recognition of key dimensions" that allow for generalizations on the premise that if it is true of one case, it must hold for similar cases using few, most relevant sources (Palinkas, Horwitz, Green, Wisdom, Duan, \& Hoagwood, 2015).

\section{Negative Labels around the World}

The use of labels has been used to create prejudice and discrimination against the negatively labeled around the world and in history. Labels have been used to create an image of inferiority in the native, low-status group, by the high-status group, regardless of which group is in the numerically minority or majority, and legitimizing the physical or psychological demeaning, devaluing, or enslavement of those of low-status. This would facilitate their submission into becoming strangers in their land, for example, and in some cases with eventual loss of their culture and language. The power of labels also empowers those who are deemed superior by exerting their dominance and increasing their self-esteem by attributing negative labels to others (Allport, 1954; Brewer, 1999; Everett et al, 2015; Tajfel, 1970).

In particular, the power of labels has been important in colonialism, where colonizers have used labels to oppress, dehumanize, and commit genocide of native populations. Exploitation theory, states that by labeling groups as "Inferior," it creates a behavior of superiority, validating the exploitation of the inferior group (Allport, 1954). Labeling the indigenous people as "Savages" legitimizes their inferiority and that they need to be controlled by a higher power to civilized them (Arteaga, 2017). Negatively labeled people around the world have led to accepted norms of inferiority of native populations. This has been essential for racism by making the native population submissive, and accept their state of inferiority. In the conquest of America, labeling the indigenous population as "backwardness, savages, primitive..." was essential to justify their exploitation (Arteaga, 2017). Labeling the indigenous population as inferior, licensed the European superpowers to submit an indigenous population by indoctrinating a belief of inferiority that needs to be controlled by a superior race. Below we chronicle how similar patterns of dehumanization have come about from the powerful effects of negative labels across the continents of America, Africa, and Australia.

\subsection{American Continent}

The Spanish empire created a caste system of skin color to attribute certain political and social-rights. The Spanish created a 16-different racial categories catalog in order to rank their social hierarchy: Gachupines were Spaniards born in Spain and who had most of the power, Criollos were Spaniard born in Mexico, Mestizos were mixed blood between natives and Spaniards, Mulatto were mixed Spaniards and African slaves, etc. (Levitin, 2011). Everyone below Gachupines was designated as inferior, and when a baby was born, a caste title was assigned, hence labeling that baby for life (Levitin, 2011). Also, the caste system had different tax rates, military obligations, degrees of punishment for criminal offenses, and enslavement (Theodore, 2001). Moreover, one of the main reasons of the Mexican independence movement was the inequality due to the caste system, where only a minority (Gachupines) had all the power in Mexico. In 1812, during the Mexican Revolution, Vicente Guerrero who is one of Mexico's heroes for independence, sought to make peace with the Spanish empire and still be part of their empire. However, Spain was unwilling to change some old caste laws, hence making Mexico fight for their independence, being finalized in 1821 (Theodore, 2001). The caste system was eventually abolished in 1821 after Mexico's independence, although the social labels continued. Under the caste laws during the Spanish empire, only people of African descent could be slaves. When the caste system was abolished, slavery was the only law still legal. Therefore, Vicente Guerrero who was a Mulatto (Black and White ancestry) abolished slavery when he became president. Unfortunately, he was kidnapped three months after passing the abolition decree and executed in 1831 (Theodore, 2001).

Similarly, Southern American countries have experienced prejudice and discriminatory behavior. In Peru, the indigenous people have been described as irresponsible, without ambition, submissive, and being insensitive (Rios-Molina, 2019). Ascribing native Peruvians with discriminatory labels created a perception that they are an inferior race. This has emboldened other "superior" groups to marginalize the native Peruvians. Furthermore, labeling groups with inferior traits and behavior is a way to make them forget where they come from. The native Peruvians are descended from the Inca Empire, one of most recognized indigenous civilizations that built extraordinary infrastructures in difficult terrain, agriculture, created a centralized economy that helped them expand rapidly, and created fortified buildings that are still standing today, for example, Machu Picchu ("Achievement Of," n.d.). Nevertheless, attributing native Peruvians demeaning labels allows the native population to forget their rich history and believe their inferiority.

Likewise, in Brazil, the same labels were put on the indigenous groups by Portugal. The social classification was also attributed to the skin color, like the Spanish social classification. On top of the pyramid were Portuguese and other European born individuals. Native 
populations were heavily targeted because of their way of living and labeling them with animal-like traits that served the purpose to dehumanize them. For example, the Botocudos fiercely protected their lands. As a result of their humble way of living and their resistance from colonization by the Portuguese, they were labeled as brutes, having ape-like customs, savages, and simians (Arteaga, 2017). As Arteaga state, "Botocudos were described as living fossils" (p. 296). In other words, assigning animal-like labels to the Botocudos made them be perceived as less evolved and belonging to a less developed time of human history.

In the United States (U.S.), the usage of labels for groups considered inferior have been used during the colonization of North America by the British. After the war of independence, only Whites had full rights, while Native Americans and enslaved Blacks were still oppressed. Slavery is one of the darkest times in U.S. history in which Blacks were portrayed as "subhumans" and "monstrous" to imply their inferiority (Weaver, 2019). Like other disenfranchised groups in the Americas, negatively labeling Blacks dehumanizes and stigmatizes them. Furthermore, the one-drop rule - or having a Black person in one's genealogy, labels an individual as Black regardless of phenotype. This classification is the only place in the Americas. In comparison to Brazil, Franklyn Frazier, American sociologist, asserts that the difference for Brazil not having the one-drop rule is that people see each other as humans, whereas, in the U.S., the word Negro is a "Symbol or stereotype" (as cited in Skidmore, 2003). Moreover, labeling groups with inhuman traits creates a stigma of inferiority that serves as a symbol to stereotype not only Black but also individuals with any percentage of Black blood. The treatment towards Native Americans was similar to the treatments of other natives in the Americas by European colonization. The Trail of Tears, which is one of the most notable acts of discrimination towards Native Americans was due to them not being "civilized," and not deserving of their land ("Trail Of," 2019). Additionally, the Trail of Tears consisted of relocating tribes from their homeland to middle America, which they had to walk more than 5000 miles and nine different states ("Trail Of," 2019, para. 11).

\subsection{African Continent}

In South Africa, the use of labels came with an agenda in order to justify the exploitation and colonization of the native people. They were labeled as sub-humans in order to portrait Black South Africans as inferior to Whites, and that they were inherently bad (Cooper, 2014). Referring to groups as subhuman creates discrimination that can have immediate and serious social consequences, including but not limited to segregation, exclusion from certain types of jobs, and less political power (Allport, 1954). In addition, during the apartheid era in South Africa, the labels of "subhuman" allow for the oppression and exploitation of the majority Blacks with the help of psychology, which created a perception of inferiority (Cooper, 2014). Also, in the Tutsi genocide in Rwanda, the prejudice and discrimination that comes from labeling a group inferior can have adverse consequences. Between 800,000 and two million people lost their lives in four months (Andre, 2018). Before the colonization of the Belgians, the Tutsis and Hutus did not see each other as superior or inferior. However, colonization from European countries created a division between the two groups by attributing different social status. As John H. Speke, a British explorer in the 1860s describes Hutus as a "primitive race" with specific physical traits "flab-nosed and pouched-mouthed Negro," while asserting that the Tutsis "descended from the best" because they had more European traits (as cited in André, 2018). Furthermore, the connotation that Tutsis were superior created resentment and hatred from the Hutus, which became a strong predictor of the attempted genocide of the Tutsis in the 1990s.

\subsection{Asia and Australian Continents}

Currently, in India, there have been lynching cases toward Kurariar and Dalits, which are nomadic tribes. The media has labeled a lynched person from any of these groups as "nuts," which means that they are part of a criminal tribe (Kolekar, 2008). The label of nuts was originally given from the British to any tribe the resisted British rule and that kept their nomadic life. Furthermore, they are still seen as criminals, which show that labels can stigmatize groups throughout time (Kolekar, 2008). Additionally, this makes them vulnerable to lynching in order to keep the social order and to prevent further influence from them in the dominant classes (Louis, 2007).

Like the native peoples of the Americas, Australia aboriginals had a similar fate. Negative labels were ascribed to the aboriginals in order to justify their exploitation. Father Perez, an influential catholic missionary, describes the aboriginals as primitive, and immature (as cited in Tatz, 2016). Similarly, to negative labels of peoples in the Americas, Australians called Aboriginals primitive in order to justify appropriation of local lands and oppression of locals. Also, Chinese immigrants in Australia were given discriminatory labels. They were labeled as "diggers" by the British in order to validate their inferiority (Smithers, 2011).

\section{Discriminatory Labels}

In this study, we have arranged the labels into internal (biological) and external (social construction) characteristics. We designated internal labels that are used 
to demean a person base on their physical traits. Such as "subhuman," a label that is meant to justify their inferiority by acknowledging their physical traits as deviant; for example, labeling Hutus as "flab-nosed" (as cited in André, 2018). Furthermore, we analyze if these labels are nouns or adjectives. The famous geneticist James Watson proclaimed various racist statements about African Americans. He argued that African Americans had an over-active sex drive because of their melanin and described them as lazy (anonymous, 2007). Cattell, American psychologist and eugenicist, uses adjectives to validate the biological inferiority of people with African descent in order to justify their exclusion from holding more impactful jobs. Also, Watson refers to them as fat and pointed out their inferiority by their high melanin (anonymous, 2007). In this case, he preferred to use noun words. In doing so, he identified the person on their biological traits. As mentioned before, the Botacudos in Brazil were referred to as having ape-like customs and primitivism. These adjective concepts attributed animal-like traits to low status individuals from those in high status groups. Asserting that they have ape-like traits and that their primitivism makes them biologically closer to animals than with humans is a form of exercising power over low status individuals, hence, making their inferiority more noticeable. Additionally, calling them simians and other native groups as savages validated a biological inferiority.

For external labels, they are labels that reflect their environment, nurture, and social construction that acknowledges their inferiority. For example, the caste system in Mexico ranked people based on their race. Moreover, labels such as Chinaman and Negro were stigmatizing stereotypes that Cattell, the American psychologist, used to describe people of Asian and African descent (as cited in Tucker, 2005). The terms Chinaman and Negro is a social issue, not a biologically reference because there is not a relationship between Chinaman and a person of Asian characteristics. The arbitrariness of the word is a social contrast created to categorize individuals into groups. The categorization of the group saves people the time to have to analyze each member separately, allowing them to create schemas for easier stereotyping (Allport, 1954). Moreover, Chinaman and Negro are nouns that place people who purportedly fit these artificial groups' characteristics in the same group. The use of adjectives to refer to a certain group can create prejudice towards them. For example, Cattell, refer to the Jewish community as a "parasitic intruder" because of their presence in many European countries (as cited in Tucker, 2005).

\section{Target of Label}

The use of labels can have negative outcomes. Use of discriminatory labels can create prejudice attitudes, escalating to more serious consequences. Allport (1954) stated that prejudice can create a sequence of rejection for outgroups. The first stage is verbal rejection (prejudice), often hostility is reflected with name-calling. Eventually, it reaches discrimination, like denying equality and segregation. The rejection of the outgroup can reach the point of physical attacks, to cause physical harm and even death. At this stage, the main purpose may be to commit genocide. Labeling individuals leads to different target outcomes, such as oppression, dehumanization, genocide, and humanization.

\subsection{Oppression}

Oppression as the objective of a label is intended to keep a person subjugated. Subjugation of a group limits their rights, discriminates against them by denying certain jobs, reducing their political influences and, curtailing their right to live freely. Moreover, categorizing people inaccurately can have a negative outcome; for example, in a Guatemalan community, they fear the Jews, although they never met one (Allport, 1954). Labeling people does not only affect them in a specific place, but also beyond borders by demonizing them and creating fear. Another example is the caste system in Latin America, which based on a group's label, excluded them from social and political power. Also, lynching can serve as a tool for oppression. Lynching is a form of vigilantism that was mostly used in the 20th century to oppressed non-White groups and enforce White supremacy in the U.S. (Hair \& Wood, 2013). Additionally, the lynching of Blacks became prevalent in the South after the American civil war for social control and oppression. Before the civil war, Mexicans, Native Americans, and some Whites were lynched, mostly in the frontier. Similarly, in India minority groups have been lynched in order to keep the social order and prevent them from becoming more involved in politics and other activities that are for the dominant class (Louis, 2007).

\subsection{Dehumanization}

Groups and individuals are dehumanized when they are discriminated against because they are perceived to not have human qualities. We mentioned before that lynching can be a form of oppression, yet, it can also be a way to dehumanize people. Lynching was justified by claiming that African Americans were behaving as "brutes" since their emancipation, which served to portray Blacks as sub-humans, monster-like, and criminals (Weaver, 2019). Often this dehumanization criminalized individuals. Lambrosos' (Bretherick, 2019) born a criminal theory, asserts that certain people are predisposed to crime because they are biologically prone to commit crimes (Ramsland, 2009). He labeled those individuals as 
"evolutionary throwbacks" because of their physical abnormality (broad nose, long arms...) that are similar to an ape-like ancestor (Ramsland, 2009). Moreover, natives in America were dehumanized by assigning labels that link them with ape-like ancestors.

\subsection{Genocide}

At a genocide level, the aim is to exterminate a group. The word genocide was coined by Raphael Lemkin in response to the systematic killing of Jew in Nazi Germany ("Genocide," n.d.). The United Nation defines genocide as:

any of the following acts committed with intent to destroy, in whole or in part, a national, ethnical, racial or religious groups, as such: killing member of the group; causing serious bodily or mental harm to members of the group; deliberately inflicting on the group conditions of life calculated to bring about its physical destruction in whole or in part; imposing measures intended to prevent births within the group; forcibly transferring children of the group to another group (“Genocide," n.d.).

In Australia, the aboriginals were subject to genocide, Meston, a Scottish journalist, stated that Aboriginals were constantly hunted like wild beast; where in the course of 25 years a tribe of 3000 members was decimated to approximately 100 members (Tatz, 2016). In India, the lynching of nomadic tribes is a genocidal act because their purpose was to deliberately cause bodily harm and death. From 1976 to 2000, there have been over 100 massacres of protesters who were hunted and killed (Louis, 2007). Perhaps, one of the lesser-known case of genocide is the genocide of Native Americans. Native Americans were deliberately attacked with malicious intent to exterminate all members of the tribe. Most of them lost their identity, language, and homeland. For instance, Peter Burnet, who was California's first governor in 1851, declared war towards the Native Americans of California until they were extinct (Oxford, 2019). Recently, Governor Newsom apologized to the Natives of California, and call their treatment as a genocide (Oxford, 2019).

\subsection{Humanization}

So far, we have reviewed the negative impacts and outcomes of labels. Nevertheless, they can also be used to create positivity and humanize stigmatized individuals. In their study, Clark and Clark (1950) brought awareness of the inequality and the effect of segregation in African Americans communities. In their doll experiment, they found that young African American girls could already distinguish a person's status in society due to their skin color. They propose that positive education programs should be created to amend labels of inferiority that have stigmatized the African American community. Furthermore, their findings were important to end segregated schools in the supreme court case of Brown vs. The Board of Education, which ended the segregation of American public schools (Beschloss, 2014). In South Africa, the goal after apartheid was to become a more progressive country and promoting more equality. Also, the Psychological Society of South Africa (PsySSA) was formed with the goal to "enhance human well-being" in order to promote equality and fairness for social justice and to prevent human rights violations (Cooper, 2014).

\section{Methodology and Results}

Using a content analysis approach, we selected 10 sources in the form of purposive sampling to do a critical case analysis (Patton, 2002). The small sample of sources (e.g., Allport, 1954; André, 2018; Anonymous, 2007; Arteaga, 2017; Clark \& Clark, 1950; Cooper, 2014; Glăveanu, 2009; Ramsland, 2009; Rios-Molina, 2019; Tucker, 2005) were used to extract labels used against marginalized minorities, or people who are dis-empowered across countries (US, Latin America, South Africa, Australia, and Asia) and time eras in two centuries (18th and 19th). We found these sources by using search keywords of racism, science, history, racial identification, inferiority, social issues, phrenology, psychology, prejudice, discrimination and criminal. The reason for a small sample was to canvass patterns, categories, and trends in how labels have been used across times, locations, and peoples that may have generalizability using a critical case analysis (Palinkas, Horwitz, Green, Wisdom, Duan, \& Hoagwood, 2015; Patton, 2002). That is, cases that are representative, repeatable, and reproducible should generalize, even if small in number.

In all, 108 labels were extracted, with two raters using a consensus model, face validity, and inter-rater checks (numeric raw data and labels extracted can be requested from the authors). The two raters coded the labels into: (a) Label as noun or adjective. (b) Label denoting internal-external ascription--nature or nurture. And, (c) noting context of how individuals were targeted, coding if label was used to (c1) humanize-, (c2) genocide-, (c3) dehumanize-, or (c4) oppress-purposes. Raters had 100 percent agreement.

Using chi-square analysis, the results showed that labels were assigned with higher frequency to internal ascription, be as nouns (58\%) or adjectives (69\%) (ns.) (see Table 1, Figure 1). Noun to adjective ratios to target individuals showed that humanization had lowest frequency ( $8 \%$ to $7 \%$ : Nouns-Adjectives), genocide labels were next ( $6 \%$ to $13 \%)$, dehumanization $(40 \%$ to $25 \%)$, and oppression highest (47\% to 55\%) (see Table 2, Figure 2). While not statistically significant, these findings did reflect real life, with lower percentages applied to most harmful forms of targets (genocide) or those taking most time to implement (humanization). Distribution of 
internal-external ascriptions by target was the most important and statistically significant finding $(p$ $=.000)$. Humanization had all external ascriptions $(21 \%)$, genocide also had 21 percent external but three percent internal, suggesting social construction being most relevant. Dehumanization (40\%) and oppression (57\%) were characterized by internal ascriptions, or nature/biological labels (see Table 3, Figure 3). Thus, vitriolic outcomes have more to do with social value interpretations of differences rather than true differences. Social construction of differences was even more marked for humanization, perhaps highlighting the need for cognitive restructuring that is required for that process.

Table 1. Percent Distribution of Words Classified as Noun Versus Adjective by Internalized- or Externalized-Term (Nature versus Nurture).

\begin{tabular}{|c|c|c|c|}
\hline & & \multicolumn{2}{|c|}{ Ascription } \\
\hline & & Internal & External \\
\hline Word & Noun & 58 & 42 \\
\hline & Adjective & 69 & 31 \\
\hline
\end{tabular}

Note: $X^{2}(1, N=108)=1.32, p=.172$.

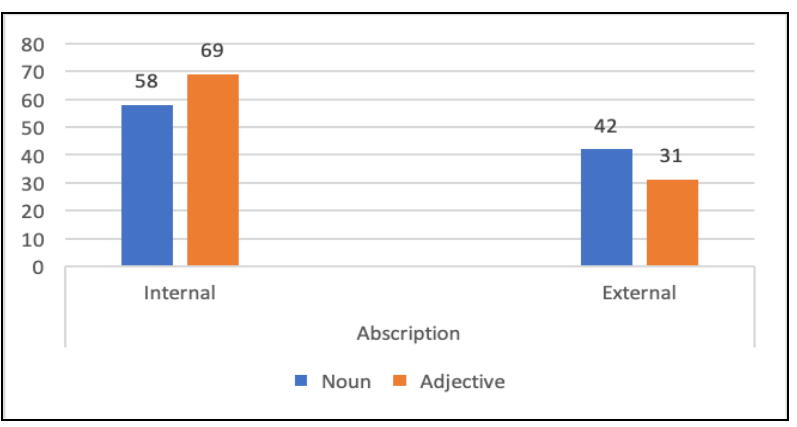

Figure 1. Percentage distribution of words ascribed as internal (Nature) or external (Nurture) for noun versus adjective. No differences were found between words classified as noun versus adjective by internalized or externalized abscription. The numbers represent the percentage distribution.

Table 2. Distribution of Words Classified as Noun Versus Adjective by Target of Bigotry.

\begin{tabular}{|c|c|c|c|c|}
\hline Word & Humanized & Genocide & Dehumanized & Oppressed \\
\hline Noun & 8 & 6 & 40 & 47 \\
\hline Adjective & 7 & 13 & 25 & 55 \\
\hline
\end{tabular}

Note: $X^{2}(3, N=108)=3.47, p=.324$.

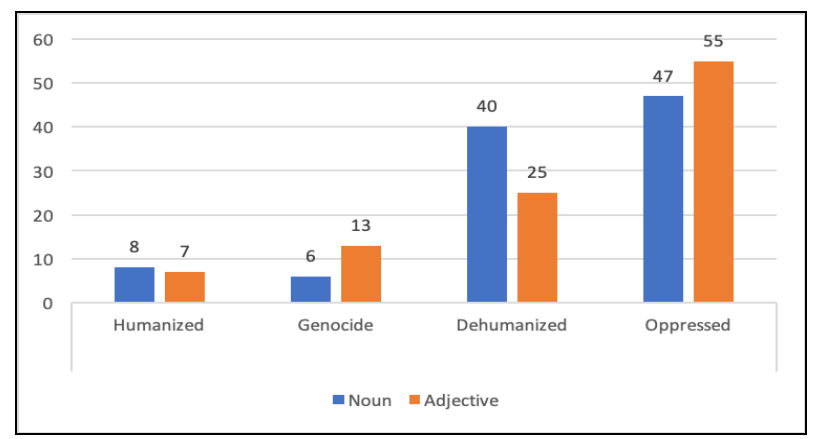

Figure 2. Distribution of words classified as noun versus adjective by target of bigotry (Humanized, Genocide, Dehumanized, and Oppressed). No differences were found from words distributed between target of bigotry and classification of words. The numbers represent the distribution of words.

Table 3. Distribution of Ascribed Word (Internal/External) by Target of Bigotry.

\begin{tabular}{|c|c|c|c|c|}
\hline & Humanized & Genocide & Dehumanized & Oppressed \\
\hline Internal & 0 & 3 & 40 & 57 \\
\hline External & 21 & 21 & 18 & 41 \\
\hline
\end{tabular}

Note: $X^{2}(3, N=108)=29.91, p=.000$.

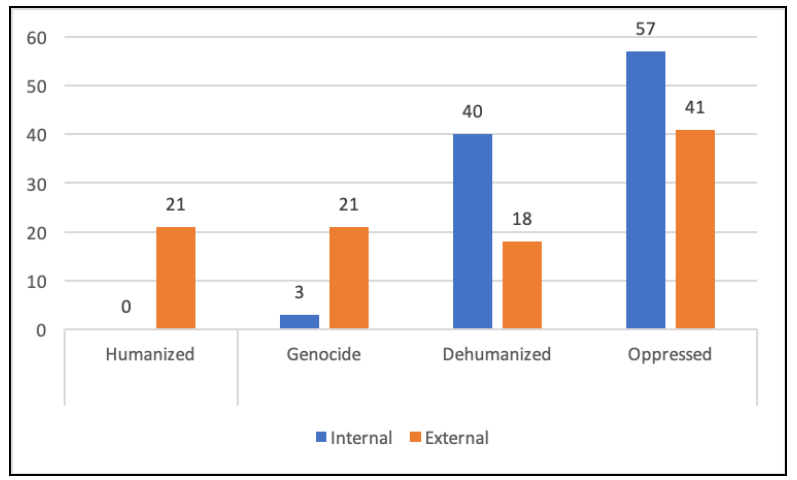

Figure 3. Distribution of ascribed word (Internal/External) by target of bigotry. Significant differences were found for ascription by target of bigotry. The numbers represent the distribution of words.

\section{Discussion}

We analyzed how labels were used to empower or disempower individuals throughout two centuries of history and in different places. During the colonization of the Americas, labeling the natives as inferior and other derogatory terms justified their exploitation and appropriation of their lands. Also, we examined how labels were used in Africa to create conflict in countries; such as South Africa and Rwanda. In Australia, the natives were indiscriminately attacked by their oppressors and had their lands appropriated. In our research, we found that recently individuals from nomadic tribes were lynched in India, depicting that many of the issues from the past are still present.

Furthermore, we classified labels as displaying internal (biological) and external (social) characteristics. Table 1 shows that adjectives are used more for labeling individuals with internal- and nouns for external-characteristics. In Table 2, we found the labels with adjective words are more common for oppressing people. For dehumanizing people, labels with noun words are more frequent. To commit genocide, labels with adjectives were more common. Allport (1954) asserts that nouns, such as a person's surname, or words used to classify people, can lead to discriminatory behavior. Also, certain labels are more salient than others and express the intent to dehumanize people. Moreover, Allport names these labels as "labels of primary potency," for example, Chinaman and Negro (p.179). 
Additionally, in Table 3, we analyzed the distribution of internal versus external labels by the target of discrimination. The table shows that for oppressing and dehumanizing groups, mainly internal labels were ascribed. Moreover, this shows that for creating prejudice and discriminatory behavior to oppress and dehumanize individuals, their physical traits and their biological characteristic are made salient. For committing genocide, we found that mainly external labels were used. Moreover, in order to get to the genocide stage, individuals are ascribed to external socially constructed labels. In addition, depicting that people are more likely to support a genocidal movement if they believe their way of living and freedoms may be under threat, a process that is known as scapegoating (Allport, 1954).

For humanizing individuals, the results show that only external labels should be used to empower people. In other words, in order to empower discriminated groups, we must change the social constructions that have labeled those groups as inferior because their phenotypes cannot be changed; however, people's perception can change. Using positive terminology to create positive attitudes and behaviors, such as the empowering phrase used by Mexican Americans in the United States, "Viva la Raza" (long live my people, Arellano, 2013). Moreover, empowering labeling can help change the perception of inferiority that many Chicanos and Hispanic children may have. Clack and Clark (1950) recommended creating programs to empower African American children in order to remove their feeling of inferiority and create positive attitudes. Similarly, creating programs to empower Hispanic children and other minorities can help embrace their cultural heritage, and at the same time being proud of being American. Empowering disenfranchised groups can also come through legislative changes such as the American Civil rights, the anti-apartheid laws in South Africa, and the anti-caste system changes in India.

Also, changing the socialization aspect of racism will create more empathy by making people realized that racism and discrimination can be harmful. Parents and community members can address these issues by holding school and community discussions to reprimand acts of discrimination, even if at cost. For instance, in a school meeting regarding discrimination and racism in the school, a father was subjected to discrimination after he was addressing how his son was suffering from discrimination (Kesslen, 2020). Discrimination is self-perpetuation and it takes effort to reduce it (Allport, 1954). Events like this help bring awareness of the ongoing issue of discrimination and to hold parents accountable for spreading bigotry. A possible solution to create more empathy toward others is to de-categorize people by removing the first word that associates people to their race, for instance, Mexican American, and regarding everyone as only Americans. However, this is easier said than done, as identity affirming labels are also important to disenfranchised groups.

\section{Conclusions}

The results depict that psychology has justified racist agendas; however, it can also promote empowerment by reversing the damage done to affected groups, in addition, by encouraging social awareness of how it has contributed to the present inequality because of unethical research done in the past. As noted, psychology justified racist plans by research agendas on the inferiority of vulnerable groups. Likewise, the field of psychology can produce research on empowering discriminated groups. As seen in our results, creating positive labels can help humanize disempowered groups. Think globally and act locally is a strategy for climate change in order to raise awareness of the ongoing environmental issues and to motivate pro-environmental behavior. Likewise, treating discrimination as a global issue of concern, can make people aware of the harmful effects of labeling individuals with negative traits, be nouns or adjectives. Humanizing individuals by showing empathy is a local issue with immediacy and humanity. Lastly, people can act if they witness discrimination by providing social and emotional support for the discriminated individual. Kindness is cheap, the right thing to do.

\section{REFERENCES}

[1] G. W. Allport. The Nature of Prejudice, Addison-Wesley Publishing Company, USA, 1954.

[2] T. F. Pettigrew. The ultimate attribution error: Extending Allport's cognitive analysis of prejudice, Personality and Social Psychology Bulletin, Vol. 5, 461-476, 1979.

[3] Colvin J, Trump Continues to Cast Some Immigrants as Criminals, Online available from https://www.pbs.org/news hour/politics/trump-continues-to-cast-some-immigrants-ascriminals

[4] M. Q. Patton. Qualitative Research and Evaluation Methods ( $3^{\text {rd }}$ ed.), Sage, USA, 2002.

[5] L. A., Palinkas, S. M. Horwitz, C. A. Green, J. P. Wisdom, N. Duan, K. Hoagwood. Purposeful sampling for qualitative data collection and analysis in mixed method implementation research, Adm Policy Ment Health, Vol. 42, 533-544, 2015.

[6] M. B. Brewer. The psychology of prejudice: Ingroup love and outgroup hate? Journal of Social Issues, Vol. 55, 429-444, 1999.

[7] J. A. C. Everett, S. F. Faber, M. Crockett. Preferences and beliefs in ingroup favoritism, Frontiers in Behavioral Neuroscience, Vol. 13, 2015.

[8] H. Tajfel. Experiments in intergroup discrimination, 
Scientific America, Vol. 223, 96-102, 1970.

[9] J. Arteaga. Biological discourses on human races and scientific racism in Brazil (1832-1911), Journal of the History of Biology, Vol. 50, No. 2, 267-314, 2017.

[10] Levitin C, The Mexican Caste System, Online available fromhttps://www.sandiegoreader.com/weblogs/fulano_de $t$ al/2011/nov/04/the-mexican-caste-system/\#

[11] V. G. Theodore. The contributions of Mexico's first Black Indian president, Vicente Guerrero, Journal of Negro History, Vol. 86, No. 2, 148-159, 2001.

[12] A. Rios-Molina. Racial degeneration, mental hygiene, and the beginning of Peruvian psychiatry, History of Psychology, Vol. 22, No. 3, 225-243, 2019.

[13] Achievement of the Incas, Online available from http://www.discover-peru.org/achievements-of-the-incas/

[14] M. Weaver, 'Judge Lynch' in the court of public opinion: Publicity and the de-legitimation of lynching, American Political Science Review, Vol. 113, No. 2, 293-310, 2019.

[15] T. E. Skidmore. Racial mixture and affirmative action: The cases of Brazil and the United States, The American Historical Review, Vol. 108, No. 5, 1391-1396, 2003.

[16] Trail of Tears, Online available from https://www.history.com/topics/native-american-history/trai 1-of-tears

[17] S. Cooper. A synopsis of South African psychology from apartheid to democracy, American Psychologist, Vol. 69, No. 8, 837-847, 2014.

[18] C. Andre. Phrenology and the Rwandan genocide, Arquivos De Neuro-Psiquiatria, Vol. 76, No. 4, 277-282, 2018.

[19] S. Kolekar. Violence against nomadic tribes, Economic and Political Weekly, Vol. 43, No. 26/27, 569-571, 2008.

[20] P. Louis. Lynching in Bihar: Reassertion of dominant castes, Economic and Political Weekly, Vol. 42, No. 44, 26-28, 2007

[21] C. Tatz. Australia: The 'good' genocide perpetrator? Health and History, Vol. 18, No. 2, 85-98, 2016.

[22] G. D. Smithers. Frontier Justice: Lynching and Racial Violence in the United States and Australia, Palgrave Macmillan, USA, 2011.
[23] Anonymous. The Nobel laureate who proclaimed the genetic inferiority of the Black race, Journal of Blacks in Higher Education, Vol. 57, 89, 2007.

[24] W. H. Tucker. The racist past of the American psychology establishment, Journal of Blacks in Higher Education (Theodore Cross Family Charitable Foundation, No. 48, 108-112, 2005.

[25] W. Hair, A. Wood. Lynching and Racial Violence, University of North Carolina Press, USA, 2013.

[26] Bretherick D. The 'Born Criminal'? Lombroso and the Origins of Modern Criminology, Online available from https://www.historyextra.com/period/victorian/the-born-cri minal-lombroso-and-the-origins-of-modern-criminology/

[27] K. Ramsland. The measure of a man: Cesare Lombroso and the criminal type, Forensic Examiner, Vol. 18, No. 4, 70-72, 2009.

[28] Genocide, Online available fromhttps://www.un.org/en/gen ocideprevention/genocide.shtml

[29] Oxford A. California Governor Calls Native American Treatment Genocide, Online available from https://apnews.com/982b507a846a4ad6bc184b3e7f99ec70

[30] K. B. Clark, M. P. Clark. Emotional factors in racial identification and preference in Negro children, Journal of Negro Education, Vol. 19, 341-350, 1950.

[31] Beschloss M. How an Experiment with Dolls Helped Lead to School Integration, Online available from https://www.nytimes.com/2014/05/07/upshot/how-an-exper iment-with-dolls-helped-lead-to-school-integration.html

[32] V. Glăveanu. Race psychology between "guilty science" and "innocent politics." Europe's Journal of Psychology, 83-95, 2009.

[33] Arellano G. Ask a Mexican: What Does "Viva la Raza" Mean. Online available from https://www.riverfronttimes.c $\mathrm{om} /$ stlouis/ask-a-mexican-what-does-viva-la-raza-mean/Co ntent?oid $=2503935$

[34] Kesslen B. 'Why Didn't You Stay in Mexico?' Online available from https://www.nbcnews.com/news/us-news/w hy-didn-t-you-stay-mexico-man-heckles-latino-dad-n11305 51 